\title{
EXPERIMENTAL TRANSMISSION OF RHEUMATIC FEVER
}

BY

\section{W. S. C. COPEMAN}

The opportunity arose in 1942 of obtaining certain adult volunteers for an experiment on the transmission of rheumatic fever in blood. This experiment will be recorded in full, although it is realized that owing to its limited scope it is not of great scientific value. It is, however, believed to be the only one of its type on record, and it is therefore of interest and seems to give experimental confirmation to certain hypotheses formulated in an article in the last issue of this journal. It was undertaken in association with Prof. Paul Beeson (then of the Harvard Field Hospital Unit), and was cut short by the exigencies of war service. Briefly it consisted in injecting the blood of a patient suffering with typical rheumatic fever into five volunteers. The blood of those who showed any reaction was then also taken and injected into a further group of volunteers; and so on. It was only in the fourth "generation " of volunteers that no further reaction of any sort was noted.

\section{SOURCE OF INFECTION}

The original donor case of rheumatic fever was a man (A. D.), aged 24, married, with no children. Father had rheumatism which started in childhood. Patient had all childish diseases. Pleurisy at the age of 12 , which kept him in bed for several weeks on suspicion of tuberculosis. In Army bakery 2 years. No rheumatism. Quinsy, 2 months and again 2 weeks previously to onset of present illness. On Dec. 20 he awoke with acute pain on outer aspect of right knee. This pain was cramp-like, and he had to flex and immobilize it to get any relief. Poulticing and painting with iodine also gave relief. Next day he was able to walk about, although he noticed that both knees were swollen. He slept well, but next morning his knees were very stiff, rather painful, and more swollen. In addition he had pains elsewhere, chiefly round the shoulders. Given light duty and lotion.

On fourth day the pains were all much worse, and the knees so swollen and painful that he could not get up. Towards evening he seemed ill, was sweating profusely, and had a temperature of $103^{\circ} \mathrm{F}$. He was then admitted to hospital. Next morning he still felt very ill and complained of headache and pains round the shoulders, and inability to move either knee owing to pain and swelling. He was still sweating profusely, but his temperature was only $100^{\circ} \mathrm{F}$. All the muscles of the lower limbs seemed tender and the first cardiac sound was muffled. The spleen and liver were not palpable. The urine was very acid. The B.S.R. was $40 \mathrm{~mm}$. (Westergren). Red blood count, normal. W.B.C., 8175 per c.mm. A sample of blood was taken for the purpose of the experiment. Next day his condition was similar, but on the following day the pains had disappeared and the temperature fell to normal and severe labial herpes developed. He made a good recovery, which was interrupted by an attack of bronchitis from which he took some time to recover, and during which the pains returned mildly. Before discharge he complained of lumbar pain, found to be due to " myalgic spots" at the borders of the lumbar muscles. A faint systolic murmur which had appeared at apex during the first week after admission was still present, and he complained of some dyspnoea on moderate exertion.

A month after the onset, when the temperature had been normal for about 20 days but the B.S.R. was $19 \mathrm{~mm}$., a further specimen of blood was taken and injected into 5 other volunteers, with no result whatever.

\section{CLINICAL OBSERVATIONS ON VOLUNTEERS}

Dec. 28, 1941.-Blood from patient A. D. taken at 9.15 a.m. and injected intravenously at $2.15 \mathrm{p} . \mathrm{m}$. to the following five persons, each of whom received $5 \mathrm{c} . \mathrm{cm}$.: D. F., G. I., J. L., and 2 others.

Dec. 31.-D. F. complained of pain in the left shoulder two days after injection; no other complaints. A tender spot could be palpated along the upper border of the left trapezius. On the afternoon of Dec. 29, G. I. complained of not feeling well; temperature was $102^{\circ} \mathrm{F}$. (axilla). At 5.30 p.m., put to bed; complained of headache. That night there was definite pain on moving the right arm. Temperature on morning of Dec. 30 was $99 \cdot 4^{\circ} \mathrm{F}$. (axilla) but normal that evening. On examination the patient appears "washed out." Complained of a pain at the upper part of the back of the neck, but no definite area of tenderness found there. Also complained of pain in the region of the right triceps brachialis and in the right lumbar muscles. No sharp localization could be detected. On Dec. 30 at 3.30 p.m. J. L. complained of headache. $\mathrm{T}=99.8^{\circ} \mathrm{F}$. (axilla); no other symptoms. On Dec. 31 temperature was $100^{\circ} \mathrm{F}$. (axilla). On physical examination a tender spot was found in the right trapezius about the mid-line; no nodule felt. Patient had no difficulty in moving arms or turning head. Defibrinated blood from G. I., and J. L., pooled and inoculated intravenously as follows: M. O. and 3 others, $4 \mathrm{c.cm}$.

Jan. 4, 1942.-G. I. still appears ill. Temperature this morning $99^{\circ} \mathrm{F}$. (axilla). Complained of pain in right lumbar region near the spine, back of the neck near the insertion of the trapezii into the occiput, and right arm region of deltoid muscle. Tenderness difficult to estimate; no spasm found. Blood taken for B.S.R. (50 mm.) and culture; $25 \mathrm{c} . \mathrm{cm}$. defibrinated for further transfer. J. L.: No more fever, no complaints, no tenderness, discharged. D. F.: No more pain in left shoulder; still slight tenderness in the left trapezius. M. O.: No symptoms or signs now, but states " a day or two ago" she had fairly severe pain in left side of the neck region and upper portion of the trapezius. No tenderness there now. The three others had no signs or symptoms following inoculations made with fresh defibrinated G. I., J. L., blood except that in one of them temperature rose to $100^{\circ} \mathrm{F}$. at night. No complaint of pain, and no subsequent symptoms.

P. R. and three others each received $4 \mathrm{c.cm}$. intravenously from $G$. I.

Jan. 11.-G. I. appears better, but is weak and shaky; still in bed; temperature normal for past week. Still complains of pain in three regions mentioned previously; no tender spot detected. P. R. on Jan. 6, complained of pain in region of insertion of left deltoid. Next day complained of pain in arm and left side of back of neck (trapezius medial to left scapula). On Jan. 8, had pain in both lumbar muscle groups and left upper gluteal region. On Jan. 9, complained of pain in lumbar and gluteal regions and in left chest, about the sixth interspace, lateral 
aspect. To-day she looks miserable, and there is marked tenderness in the above-mentioned areas. The thoracic area is particularly tender. She has never had any elevation of temperature. Blood taken for culture, B.S.R., etc., and also defibrinated and $4 \mathrm{c.cm}$. inoculated intravenously into $\mathrm{S}$. U. and three others.

Jan. 12.-S. U. had temperature of $99 \cdot 8$ F. (axilla) in morning, $97^{\circ} \mathrm{F}$. in evening. Complained of pain in right arm, below elbow. Jan. 13: $\mathrm{T} .=99 \cdot 2 \mathrm{~F}$. in morning, $97.6^{\circ} \mathrm{F}$. in evening. Jan. 14: $\mathrm{T}=99.6 \mathrm{~F}$. in morning, 97 $\mathrm{F}$. in evening. Jan. 15: $\mathrm{T} .=98.8 \mathrm{~F}$. in morning. Patient examined; no specific complaint obtainable: no tender area found. Blood taken for usual studies and for transfer. G. I.: No fever, no complaints, no physical signs. P. R.: Patient better, but still complains of pain in lower part of back: still has some tenderness in lumbar region, and over lower ribs bilaterally.

Jan. 16.-About Jan. 7 Nurse H., who was attending these patients, wakened in night with severe pains in legs, above, below, and in the knees. Movement was painful. Pain extended up and down both lower extremities, even involving both gluteal regions. There was one especially tender spot on the right thigh, three inches above the knee. The pain seemed worse when lying still, and she could get no rest in bed. She sat up most of three nights. She vomited six times in four days. No numbness or tingling. No pain above the hips. She had no respiratory symptoms. No feverish or chilly sensations. No headache.

Jan. 16. - 3 c.c. defibrinated blood (3 c.cm.) from S.U. inoculated into 4 other volunteers with no result.

Jan. 22.-Nurse H. still has pains in backs of legs. For three days last week she had pain and stiffness in back of neck (both trapezii), with limitation of movement. She still has trouble in sleeping because of the pain. No fever or headache. G. I.: Up last week, no pain. P. R.: About the same. Still tender in previously described areas. To be allowed up in 2 days. Developed some pain on getting up, and on Feb. 2nd was reported as ? chronic fibrositis. S. U.: Still in bed, no fever, no apparent pain, but? slight systolic murmur, apex.

\section{Summary}

From the results of this experiment (which it is realized is incomplete and insufficiently controlled) it would look as though an infective agent was present in the blood of the original patient (A. D.) with rheumatic fever, and that this was transferred on the fourth day of his illness to the volunteers, producing mild attacks of rheumatic fever in two of them (G. I. and J. L.) after 24 hours, and pain in the shoulder muscles without pyrexia-fibrositis-three days later in another (D. F.).

The blood from these first two cases was pooled on the third day and again passed on, producing what appeared to be an attack of a febrile fibrositis on the second day in one of four recipients (M. O.).

The blood of the more severely affected of the first two cases (G. I.) was again transferred, on the seventh day of his illness, to four other volunteers, one of whom (P. R.) developed a painful generalized fibrositis which six weeks later seemed likely to become chronic.

The blood of this patient (P. R.) had been transferred to four recipients on the seventh day after he himself had received his blood infection. One of these developed mild fever and generalized pains which lasted a few days only, but five weeks later a faint apical systolic murmur was heard. Blood taken from this patient on the fifth day produced no effect on four recipients.

The attack of rheumatism suffered by the nurse in attendance may have been a coincidence.

\section{Conclusion}

It might be surmised from this experiment (1) that rheumatic fever can be transmitted in the blood of an active sufferer, and (2) that the syndrome of rheumatic fever may be a synthesis of two elements, (a) a febrile non-specific element, and (b) a specific fibro-toxic (and cardiotoxic) element; since it seemed that there was some clinical evidence of these two elements developing independently in certain of the volunteers.

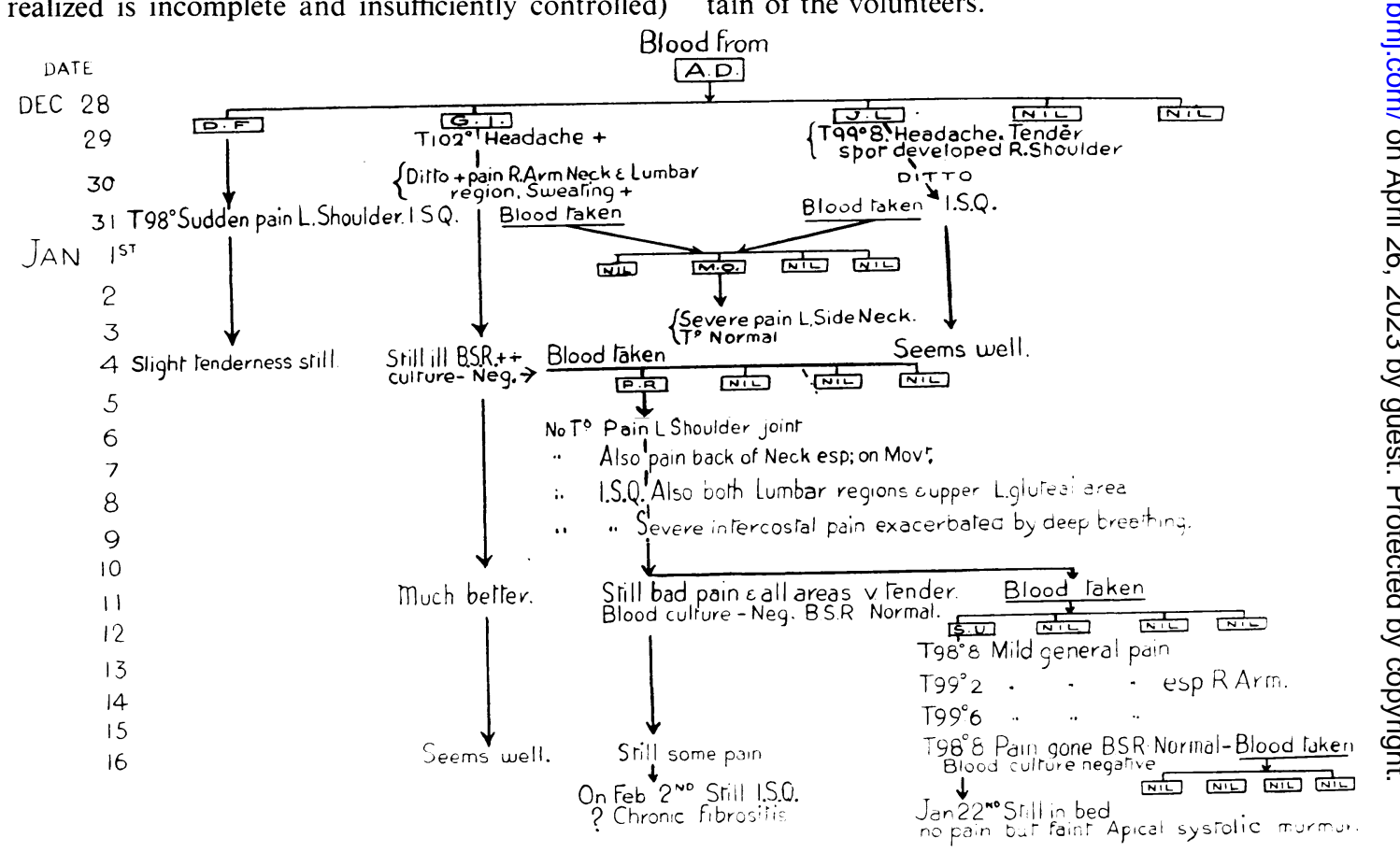

